\title{
Multiscale description and prediction of the thermomechanical behavior of multilayered plasticized PVC under a wide range of strain rate
}

\author{
C. A. Bernard ${ }^{1,2}$ (D), N. Bahlouli ${ }^{2}$ (D), C. Wagner-Kocher ${ }^{3,4, \star}$ (D) J. Lin $^{2}$ (D), S. Ahzi ${ }^{2}$ (D), and Y. Rémond ${ }^{2}$ (1) \\ ${ }^{1}$ FRIS, Tohoku University, Sendai, Japan \\ ${ }^{2}$ ICube, Université de Strasbourg/CNRS, 2 rue Boussingault, 67000 Strasbourg, France \\ ${ }^{3}$ LPMT, Université de Strasbourg - UHA Mulhouse, 11 rue Alfred Werner, 68093 Mulhouse Cedex, France \\ ${ }^{4}$ LMGC - Laboratoire de Mecanique et Genie Civil, CNRS, Université de Montpellier, 34095 Montpellier, France
}

Received: 5 February 2018

Accepted: 21 June 2018

(C) Springer Science+Business Media, LLC, part of Springer Nature 2018

\begin{abstract}
Plasticization of polymers largely contributed to their worldwide utilization, especially for automotive crashworthiness, by making them a more ductile material. For such applications, a clear understanding of the mechanical properties evolution over a large range of strain rate and temperature is needed. In this study, we investigate a plasticized poly(vinyl chloride) manufactured through a multilayered process for the automotive industry. Analysis of the microstructure before and after mechanical testing, at different temperature and strain rate, highlighted the presence of sodium aluminosilicate within material microstructure. After thermal degradation analysis, these particles seem to be the only one to remain at high temperature. Moreover, it is important to mention that for the possible applications of this material, the temperature range is around the glass transition region leading. Thus, careful attention should be focused on the evolution of the material properties and on the way to model them. Numerical prediction of the storage modulus and yield stress using homemade models show a good agreement with the experimental data. More, these models will make reliable the use of these materials over a wide range of temperatures and strain rates that are difficult to obtain by experience, such as intermediate strain rates between quasi-static and dynamic loading.
\end{abstract}

\section{Introduction}

Since the early 1970s, the part polymeric materials play in the automotive industry has strongly increased to reduce the mass of vehicles. Thus, the fuel consumption is lowered and performances are improved in terms of noise, shock absorption or lifetime. Among the polymers used in the automotive industry, poly(vinyl chloride) (PVC) is widely used for crashworthiness applications. At room

Address correspondence to E-mail: christiane.wagner-kocher@umontpellier.fr 
temperature, PVC is a glassy polymer. Several works [1-3] measured the glass transition of PVC around $82{ }^{\circ} \mathrm{C}$. However, Pezzin et al. [4] showed that the glass transition of PVC is dependent on its molecular weight. This can be explained by the PVC chain stiffness and the free volume theory [5, 6]. The conditions of polymerization are such that all samples have the same degree of syndiotacticity. Pezzin et al. [4] found that the glass transition temperature increases rapidly and asymptotically reaches the limiting value $T_{\mathrm{g}}^{\infty}=78^{\circ} \mathrm{C}$.

The PVC used in the automotive industry is generally modified by plasticizing to obtain flexible PVC. This is the so-called plasticized PVC (PPVC), where the effects of weather, road, and driving conditions are minimized. In PPVC, powdered resin is mixed with each of a stabilizer, plasticizer, lubricant, and dioctyl phthalate that explain the thermal stability of PPVC at processing temperatures [7-9].

Investigations of the mechanical response, plasticizer effect, and morphology of PPVC have been of particular interest to academic researchers and industrialists because of the widespread use of PPVC in automotive crashworthiness. Many authors [10-13] investigated the strain rate dependence of PVC and PPVC with a high-level of plasticizer, from quasistatic to dynamic loading at room temperature. They also investigated the temperature sensitivity of both materials for a strain rate of $10^{-2} \mathrm{~s}^{-1}$. For all strain rates tested, at room temperature, PVC exhibits a glassy polymer behavior, whereas PPVC shows a change of behavior between the quasi-static and dynamic loading. Thus, at low strain rates, PPVC reveals a rubbery polymer behavior, and at high strain rates, the mechanical response of PPVC is glassier. However, at room temperature, strain softening of PPVC is not observed, unlike PVC. Investigation of the temperature sensitivity clearly shows a change in the mechanical response of PPVC. For temperatures lower than $-40{ }^{\circ} \mathrm{C}$, PPVC exhibits a glassy polymer response. The yield stress is clearly identified and is followed by strain softening. Between -20 and $0{ }^{\circ} \mathrm{C}$, the mechanical response of PPVC is less glassy and a rubbery mechanical behavior is identified for temperatures above $21^{\circ} \mathrm{C}$. These authors also showed that the yield stress is bilinearly dependent on the log of the strain rate. Wang et al. [1] investigated the strain rate dependence of PPVC. Loading-unloading compressive tests at constant strain rates highlight a viscoelastic behavior of PPVC. Mulliken et al. [14] performed dynamic mechanical analyses and quasi-static and dynamic uniaxial compressive tests on PVC and 20\% PPVC. They found that the addition of $20 \%$ of plasticizers into the PVC blend decreased the glass transition temperature to $22{ }^{\circ} \mathrm{C}$. Moreover, for this level of plasticizer at room temperature, the PPVC exhibits a glassy behavior at high strain rates and the yield point is followed by strain softening. This is in contrast to the PPVC investigated by Kendall and Siviour $[10,11]$. Thus, the percentage of plasticizer in the PPVC blend is of great importance for its mechanical properties. The effects of the plasticizer content on the material properties of PPVC have been investigated previously $[15,16]$ and several observations have been made. In addition to the previous observations, the addition of a plasticizer to the PPVC blend decreases the glass transition temperature $[3,17,18]$. Moreover, while the addition of a plasticizer improves the elongation at break and increases both the fracture energy and the Poisson's ratio, it decreases the elastic modulus, the yield stress and the hardness of the material [7, 8, 19-21]. Thus, the mechanical behavior of PPVC exhibits a triple dependence on strain rate, temperature and plasticizer level. Thus, a literature review highlights strong differences depending on the PPVC and its plasticizer content. Varughese et al. [7] and Thomas et al. [22] investigated the tensile and tear fracture surfaces. Scanning electron microscopy observation on fractured surface after tensile tests showed ductiletype failure, mainly due to shear fracture with high plastic deformation, whereas the tear fractography brings out the presence of sine waves.

The purpose of this paper is to characterize and analyze the thermomechanical behavior and the deformation mechanisms of PPVC sheets obtained by a layered process. This process is not useful for the dynamic loading. Because the manufacturing process strongly influences the mechanical properties of a material, it is necessary to analyze the strain rate and temperature sensitivity of a layered PPVC at different scales. The studied PPVC is destined to components designed for the automotive industry. Thus, the PPVC structure will be submitted to high strain rates. The thermomechanical behavior of the material and its morphology were characterized: detailed thermal and mechanical analyses being performed over a wide range of strain rates and temperatures to. To 
improve the use of the layered PPVC, we propose a predictive modeling of the modulus and the threshold stress.

\section{Materials and methods}

\section{Materials}

The PPVC studied in this paper is composed of $50 \%$ PVC, $40 \%$ plasticizer, and $10 \%$ additives. The material was manufactured by Faurecia using an innovative layered process and provided as PPVC sheets of $1 \mathrm{~mm}$ thickness.

\section{Morphology}

Micrographs were taken before and after mechanical characterization, to observe modifications of the morphological aspects and defects of PPVC along its thickness. Chemical microanalyses of energy-dispersive X-ray spectra (EDS) were registered and microstructure analysis was carried out using energy-dispersive X-ray microanalysis together with scanning electron microscopy (SEM; JEOL 6700F). Sections were cut from the gauge length before and after tensile tests. The fractured surfaces were obtained by breaking PPVC specimens in liquid nitrogen to minimize the development of plastic deformation. The topology of the fracture surfaces was directly observed after iridium coating. The presence and the sizes of voids were analyzed using ImageJ and compared, before and after tensile tests for three specimens.

\section{Thermal analysis}

The thermal stability of PPVC was evaluated by thermogravimetric analysis (TGA) on a METTLER TOLEDO TGA/DSC1 machine, with the STAR system, operated in air from 40 to $1000{ }^{\circ} \mathrm{C}$ at a heating rate of $20^{\circ} \mathrm{C} / \mathrm{min}$. The mass of the specimens ranged between 15 and $25 \mathrm{mg}$. The mass loss and temperature during the test were recorded. The accuracy of the weighing machine is $1 \mu \mathrm{g}$.

Differential scanning calorimetry (DSC) tests were conducted on a METTLER TOLEDO DSC1 machine with the STAR System and a HSS8 sensor. These tests characterize the transition temperatures and analyze the phase miscibility of the material. The mass of the tested specimens was approximately $15 \mathrm{mg}$. The heating cycle was carried out for a temperature range from -150 to $250{ }^{\circ} \mathrm{C}$ with a heating rate of $10^{\circ} \mathrm{C} /$ min. A second scan was performed at the end of the first scan after quenching, to evaluate the polymer properties after removing the sample thermal history. This is erased when the material is heated above its glass transition temperature.

Dynamic mechanical analyses (DMA) were conducted under tensile loading at $1 \mathrm{~Hz}$ for a temperature range from -100 to $120{ }^{\circ} \mathrm{C}$. The glass transition temperature range was first determined by testing the sample using a $2{ }^{\circ} \mathrm{C} / \mathrm{min}$ dynamic temperature sweep at $0.2 \%$ strain and $1 \mathrm{~Hz}[23,24]$. The evolution of the storage modulus, loss modulus, and $\tan \delta$ (the ratio between the loss and storage moduli) was investigated over the range of temperature studied. The glass transition temperature measured by DSC and DMA was compared using different analysis methods to better understand the discrepancies that exist between these two thermal techniques.

\section{Mechanical characterization}

\section{Quasi-static uniaxial tensile tests}

For the quasi-static strain rate tests, uniaxial quasistatic tensile tests were conducted using an INSTRON 3384 universal testing machine equipped with a temperature chamber (500 Series Chambers) to perform mechanical tests at different temperatures. Tests were carried out at constant displacement rates, at 50 and $500 \mathrm{~mm} / \mathrm{min}$ for different constant temperatures $\left(-30,0,23,85^{\circ} \mathrm{C}\right)$. The stress-strain behavior of the samples was determined from the load-displacement data of the tensile device. At the yield point, identified on the stress-strain curves as the intersection point between the viscoelastic behavior slope and the viscoplastic behavior slope, these displacement rates lead to true strain rates of 0.03 and $0.3 \mathrm{~s}^{-1}$, respectively. The test specimens are cut from PPVC sheets by Faurecia. The specimen geometry follows the standard ASTM D412 classically used in international industries. For both temperature and strain rate, at least five samples were tested. 


\section{Dynamic uniaxial compressive tests}

For the high strain rates, uniaxial compression tests were carried out on a homemade Split Hopkinson Pressure Bar (SHPB) [25, 26] at three temperatures $\left(-30,23,85^{\circ} \mathrm{C}\right)$ and two ranges of strain rates. Two devices, one for low and one for high temperatures, were adapted on our SHPB. At high temperatures, the sides of the two bars in contact with the specimen were positioned in a homemade furnace containing two electrical resistances. For low temperatures, the specimen was sandwiched between the two bars inside a homemade temperature chamber. Then, the specimen and a short part of the bars were cooled to below $-30{ }^{\circ} \mathrm{C}$ by the addition of liquid nitrogen to the chamber. The addition of technical alcohol helps to maintain the thermal equilibrium during the tests. Four thermocouples inserted in the temperature chamber allow the temperature inside the oven to be controlled. To reach a thermal equilibrium, the samples were heated or cooled in the appropriate chamber and maintained at the target temperature for $15 \mathrm{~min}$ before testing [25, 27].

The test fixture is composed of three 22-mm-diameter steel bars. The input and output bars are $3 \mathrm{~m}$ long and the strikers are 0.5 and $1 \mathrm{~m}$ long, to reach a wider range of strain rates. These strikers are launched with an air gun against the incident bar to generate the incident pressure pulse. On impacting the input bar, the striker generates an incident pulse $\varepsilon_{\mathrm{i}}(t)$. Once this pulse reaches the specimen, one part $\varepsilon_{\mathrm{r}}(t)$ is reflected into the incident bar, the other part $\varepsilon_{t}(t)$ goes through the specimen and is transmitted to the output bar. According to the wave propagation theory, the stress and particle velocity can each be calculated at every section of the bars. In particular, they are shifted from the gauge location to both bar/specimen interfaces considering two superposed waves propagating in opposite directions at a velocity $C_{\mathrm{b}}$, which is the speed of sound into the bars when dispersion is neglected. This velocity was measured during a conventional SHPB test without specimen [28, 29]. Thus, assuming that the bars are linear with a constant section and that the deformation and forces are homogenous within the sample, we can apply the classical elastic wave propagation theory. The nominal strain rate $\dot{\varepsilon}_{\mathrm{n}}$, strain $\varepsilon_{\mathrm{n}}$, and stress $\sigma_{\mathrm{n}}$ are given by: $\dot{\varepsilon}_{\mathrm{n}}(t)=-\frac{2 C_{\mathrm{b}}}{L_{\mathrm{s}}(0)} \varepsilon_{\mathrm{r}}(t)$

$\varepsilon_{\mathrm{n}}(t)=-\frac{2 C_{\mathrm{b}}}{L_{\mathrm{s}}(0)} \int_{0}^{t} \varepsilon_{\mathrm{r}}(\tau) \mathrm{d} \tau$

$\sigma_{\mathrm{n}}(t)=2 E_{\mathrm{b}} \frac{A_{\mathrm{b}}}{A_{\mathrm{s}}}\left(\varepsilon_{\mathrm{i}}(t)+\varepsilon_{\mathrm{r}}(t)+\varepsilon_{t}(t)\right)$

where $E_{\mathrm{b}}$ is the Young modulus of the bar, $L_{\mathrm{s}}(0)$ is the initial length of the sample, $A_{\mathrm{b}}$ and $A_{\mathrm{s}}$ are the crosssectional area of the bar and the sample, respectively. According to $v$, the polymer viscosity, the true strain and true stress are identified from the nominal measurement:

$\varepsilon_{t}(t)=-\ln \left(1+\varepsilon_{\mathrm{n}}(t)\right)$

$\sigma_{t}(t)=\sigma_{\mathrm{n}}(t)\left(1-\varepsilon_{\mathrm{n}}(t)\right)^{2 v}$

Cylindrical specimens with a diameter of $10 \mathrm{~mm}$, cut from the PPVC sheets, were tested to investigate their dynamic thermomechanical behavior. For each condition (temperature, strain rate), at least five samples were tested.

\section{Results and discussion}

\section{Microstructural characterization}

The fracture surface morphology was observed by scanning electron microscopy at different visualization scales. Figure 1 shows SEM micrographs of the fractured surfaces taken perpendicular to the loading direction before (Fig. 1a) and after (Fig. 1b) quasistatic tensile tests. Due to the cooling of samples in liquid nitrogen before breakage, the material exhibits brittle fracture. The fractured surfaces reveal the presence of voids. Before testing, the percentage of voids within the specimen is around $4 \%$ and increased to $6.7 \%$ after testing. The number of small and middle size voids increase by $50 \%$, whereas the number of the larger voids is quite constant. However, it appears that their diameter highly increases (+150-200\%) after testing.

For all the analyzed specimens, the voids are well distributed with the presence of the small and middle size voids mainly located at the bottom of the specimen and the larger size voids located in the specimen core. Because the voiding appears perfectly aligned along a line, their presence and position are probably related to degassing phenomena occurring at 


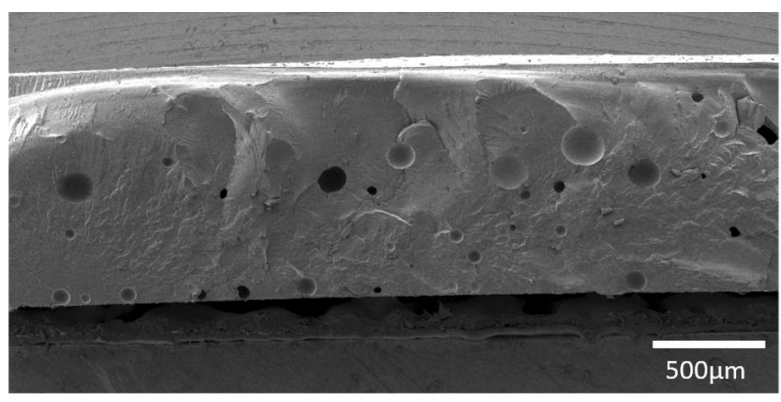

(a) Non-tested material

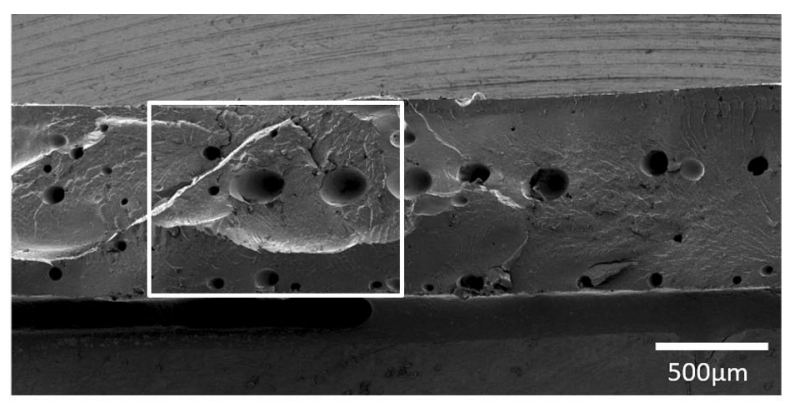

(b) Deformed material

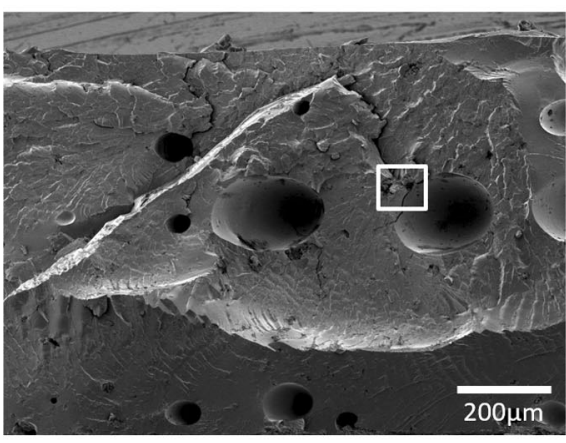

(c) Zoom 1

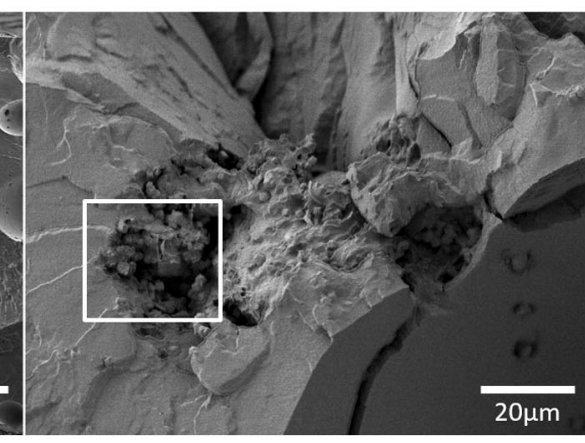

(d) Zoom 2

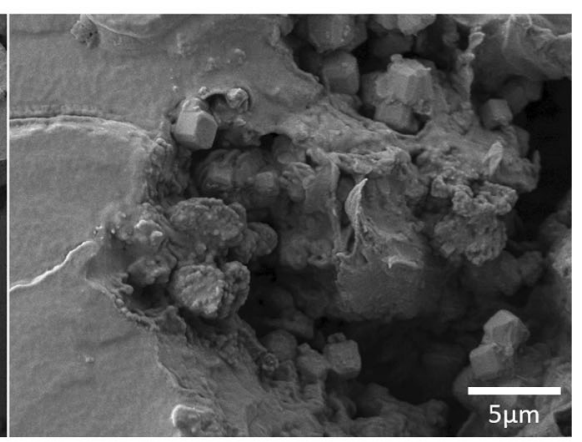

(e) Zoom 3

Figure 1 SEM micrographs of a the fractured surface of virgin material, and $\mathbf{b}$ after quasi-static tensile tests and $\mathbf{c}$, $\mathbf{d}$, e gradual magnification of $\mathbf{b}$ highlighting the presence of cubic clusters near the porosity.

different time intervals of the manufacturing process of the PPVC sheets.

Even though similar microstructures are observed before and after mechanical testing of the specimen, in terms of voids repartition, the fracture surface of the tested specimen (see Fig. 1b) exhibits some irregularities unseen in the non-tested area (see Fig. 1a). When we increase the magnification (see Fig. 1c, d, e), voids with different shapes were observed. At higher magnification, clusters of cubic particles appear (see Fig. 1e). The size of the cubic particle is approximately $1 \mu \mathrm{m}^{3}$.

Analysis by X-ray diffraction presented in Fig. $2 b$ will provide more information about sample constitution. The areas contained in the white squares shown in Fig. 2a were analyzed. Sq1 corresponds to the fractured surface outside the cluster; Sq2 is taken from inside the cluster and S3 matches one cubic nodule. The results of X-ray patterns are presented in Fig. 2 b. SEM coupled with energy-dispersive $X$-ray spectroscopy also allows highlighting of the chemical composition of the observed particles. Sq1 and Sq2 show similar chemical compositions, while S3 demonstrates a higher oxygen peak and non-negligible representative peaks of $\mathrm{Na}, \mathrm{Al}$ and $\mathrm{Si}$. In the Sq2 zone, even if the presence of agglomerates is observed, the X-ray pattern shows very low contents of $\mathrm{Na}, \mathrm{Al}$, and $\mathrm{Si}$. These elements $(\mathrm{O}, \mathrm{Na}, \mathrm{Al}, \mathrm{Si})$ are proof of the presence of sodium aluminosilicate classically used as a stabilizing component of PVC melts [30].

\section{Thermogravimetric analysis}

The thermal degradation of PPVC, characterized by TGA, is shown in Fig. 3, for three specimens to evaluate the discrepancy seen in the material. The thermogravimetry (TG) curves show the percentage of mass loss versus temperature. The DTG curves are superposed onto the TG curves and indicate the rate of mass loss used to evaluate the degradation temperature of the material. Similarly to pure PVC $[17,31]$, the thermogravimetric curves of PPVC (see Fig. 3a) show two degradation peaks around 330 and $455{ }^{\circ} \mathrm{C}$. These correspond to a loss of $73.9 \pm 2.1 \%$ and $15.4 \pm 0.3 \%$ of the initial mass. This leads to a total mass loss of approximately $90 \%$ for each tested specimen. The samples are thermally stable and the weight loss rate is almost equal to zero at temperatures below $250{ }^{\circ} \mathrm{C}$. Above this temperature, the decomposition rate falls and reaches a minimum of $-13.97( \pm 8 \%) \% \mathrm{~min}^{-1}$ at $329.8( \pm 1.27 \%){ }^{\circ} \mathrm{C}$. 


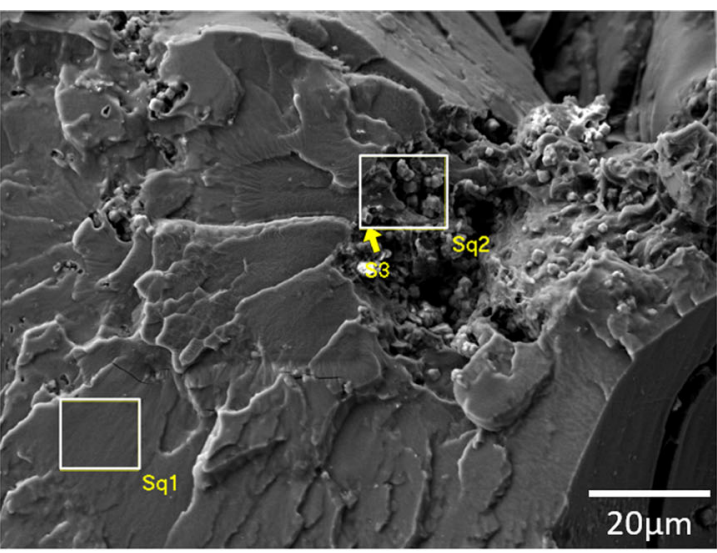

(a) Presence of three microstructures into the specimen

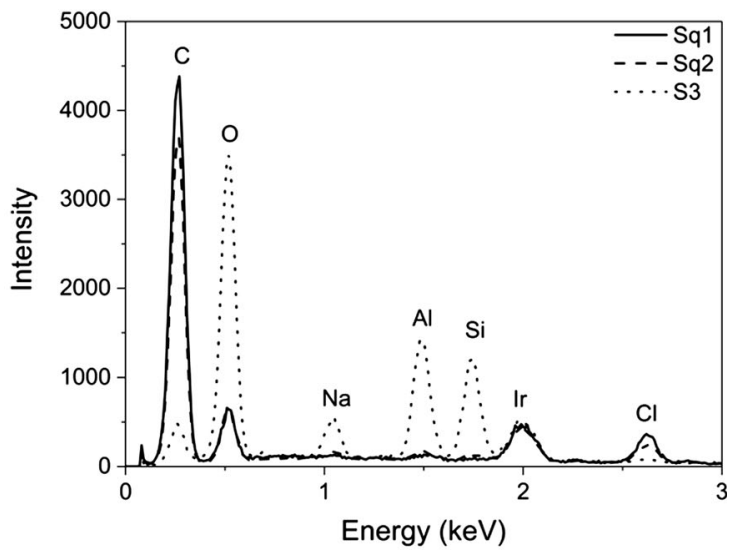

(b) X-ray pattern of the three microstructures

Figure 2 a Identification of three microstructures in the PPVC studied and $\mathbf{b}$ X-ray patterns of these three zones.

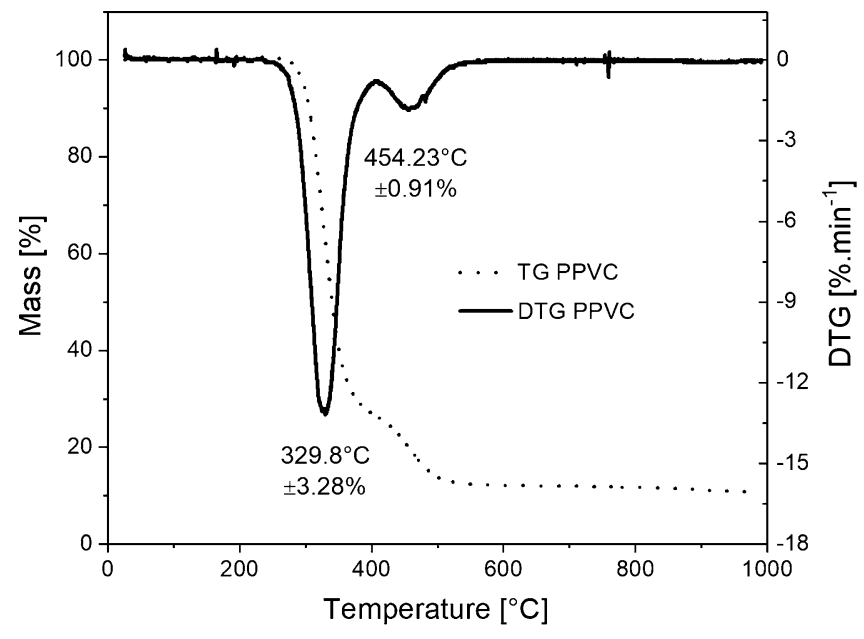

(a)

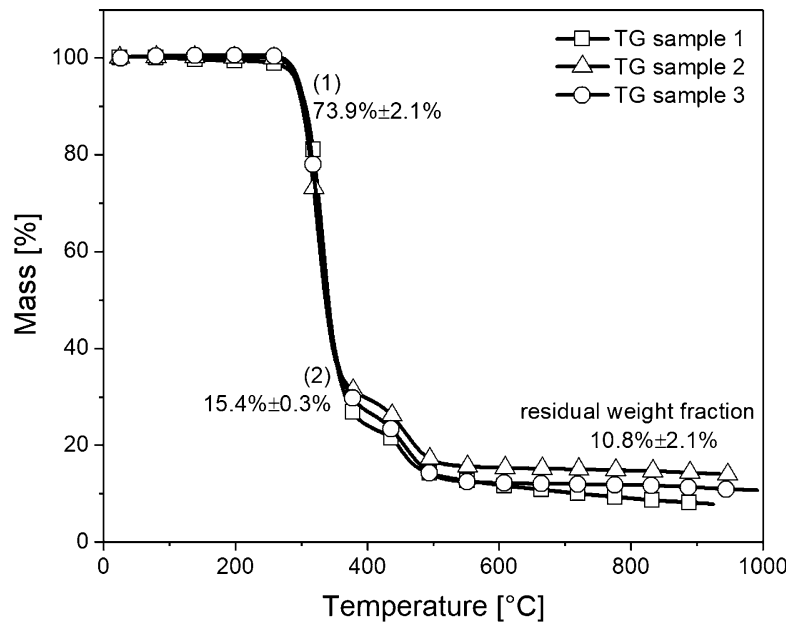

(b)

Figure 3 Thermogravimetric curves of the PPVC sheets for each thickness. a TG and DTG of PPVC sample, b superposition of three PPVC samples.

According to previous publications, [32-35], the first degradation step matches the dehydrochlorination of $\mathrm{PVC}$, with the formation of hydrochloric acid $(\mathrm{HCl})$ and conjugated polyene sequences of 5-25 double bonds. The second step is characterized by the formation of alkyne aromatic hydrocarbons and char residues, due to the rearrangement of polyene structures through cyclization and cross-linking reactions. When PPVC samples are heated above $500{ }^{\circ} \mathrm{C}$, their mass is stable. The residual weight fraction is $10.8 \pm 2.1 \%$, and this can be related to the cubic particles observed during characterization of morphology.
The thermogravimetric curves obtained for each sample are plotted in Fig. 3b. The two degradation steps are clearly identified. Between the three specimens studied, some discrepancies appear at the beginning of the second stage due to a difference in mass loss at the end of the first stage. This difference can be attributed to a variation in the quantity of $\mathrm{HCl}$ during the first step. Despite the difference in mass loss between the two degradation stages, the total degradation of the material is approximately the same at the end of the thermogravimetry analysis. According to the literature, the presence of plasticizers and additives in the PVC does not delay the first stage of deformation, however, it delays the 
second stage of the material degradation (from 454 to $466{ }^{\circ} \mathrm{C}$ for [17] and from 465 to $515{ }^{\circ} \mathrm{C}$ for [31]).

\section{Differential scanning calorimetry (DSC)}

Figure 4 shows the DSC thermograms of PPVC from $-150{ }^{\circ} \mathrm{C}$ to $+250{ }^{\circ} \mathrm{C}$ for three specimens, to evaluate the discrepancy in material properties induced by the layered process. The first heating run was carried out to remove the thermal history of the samples. The second heating run leads to the determination of the different thermal transitions of the studied polymer. The glass transition temperature of PPVC is characterized by an endothermic deviation from the baseline in the DSC thermogram. From the DSC tests, we assume that the glass transition temperature is given the midpoint of the heat-capacity shift. In the first scan, an endothermic deviation appears at approximately $-41^{\circ} \mathrm{C}$. In the second scan, the first deviation, which corresponds to the glass transition temperature, is close to $-32{ }^{\circ} \mathrm{C}$.

A second endothermic peak appears around $+65{ }^{\circ} \mathrm{C}$ on the first scan. According to the results of Wang et al. [1], this value corresponds to the glass transition temperature of unplasticized PVC. This result is in agreement with the open literature [17, 36] Indeed, it is well-known that the type and percentage of plasticizer lead to a drop in the glass transition temperature. The second scan curve is straight, suggesting complete miscibility between PVC and plasticizers.

A third peak is detected on the first scan around $+240{ }^{\circ} \mathrm{C}$, as shown in Fig. 4 . On the second scan, this

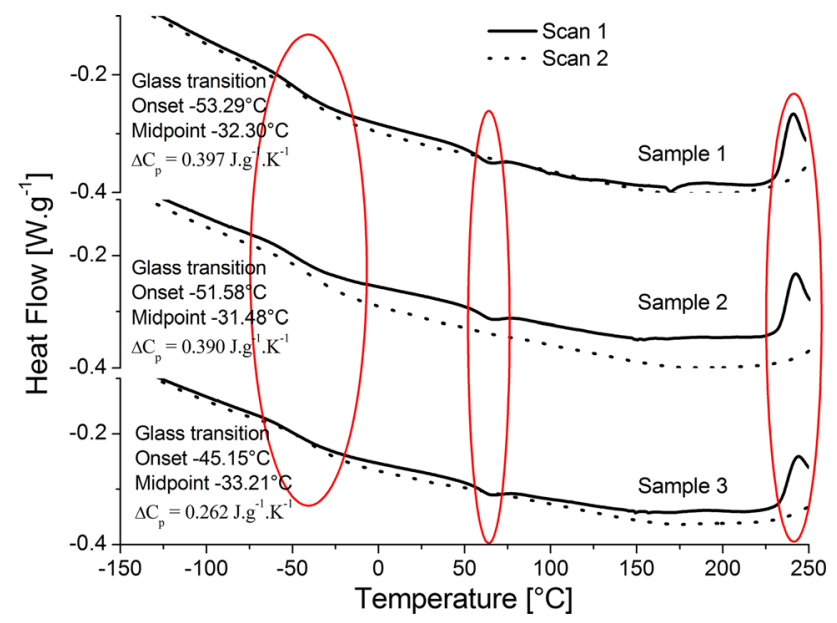

Figure 4 DSC thermograms for the two courses and three samples. peak is shifted to above $+250{ }^{\circ} \mathrm{C}$. These are exothermic peaks. A comparison between the TGA thermogram and the DSC scan leads to the conclusion that this peak corresponds to the beginning of the material degradation, which occurs around $+260{ }^{\circ} \mathrm{C}$.

\section{Dynamic mechanical analysis}

DMA tests have been performed at $1 \mathrm{~Hz}$ for temperatures ranging from -100 to $120^{\circ} \mathrm{C}$. The results are presented in Fig. 5 for storage modulus, loss modulus and $\tan$ delta $(\tan \delta)$ curves. The $\tan \delta$ curve is defined as the ratio between the loss modulus and the storage modulus.

According to the $\tan \delta$ curve, the glass transition region, at $1 \mathrm{~Hz}$, extends from -40 to $80^{\circ} \mathrm{C}$. Close to the beginning of the glass transition region, a peak is observed at around $-30{ }^{\circ} \mathrm{C}$ on the loss modulus curve, whereas another peak is observed on the $\tan \delta$ curve, at around $0{ }^{\circ} \mathrm{C}$. In the literature [37-39], a large discrepancy is observed between DMA $T_{\mathrm{g}}$ given by the $\tan \delta$ peak and DSC $T_{\mathrm{g}}$. However, Achorn and Ferrillo [35] determine a DMA $T_{\mathrm{g}}$ in agreement with DSC $T_{\mathrm{g}}$ by considering the glass transition temperature as the average of the loss modulus and $\tan \delta$ peak temperature measured at $1 \mathrm{rad} / \mathrm{s}$ (around $0.15 \mathrm{~Hz}$ ). According to this procedure, $T_{\mathrm{g}}$ is measured around $-15^{\circ} \mathrm{C}$ at $1 \mathrm{~Hz}$, higher than DSC $T_{\mathrm{g}}$ due to relative higher frequency (supposedly around $0.15 \mathrm{~Hz}$ according to the work of Achorn and Ferrillo [40]).

The discrepancy observed in the glass transition temperature between DSC and DMA can be explained by: (a) these two techniques involve

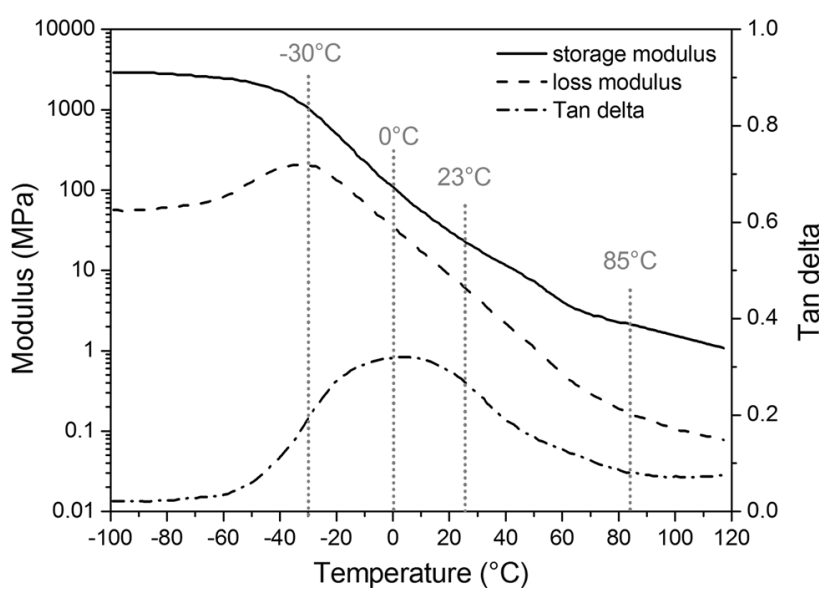

Figure 5 DMA curve plotted at $1 \mathrm{~Hz}$. 
different material states during the analysis, (b) since the operating conditions between DSC and DMA differ, the thermal equilibrium within the material is not the same. Thus, because the glass transition is a thermally activated process, it is expected to observe such discrepancy between two different measures. Moreover, DSC measurements are known to be more thermodynamically stable than DMA where thermal gradients can occur inside the sample whose geometry and weight are quite different from DSC.

Throughout the entire glass transition region, we observe a major drop in the storage modulus, from $3 \mathrm{GPa}$ to around $2 \mathrm{MPa}$. Thus, for temperatures below $-50{ }^{\circ} \mathrm{C}$, PPVC is in its glassy state, while for temperatures above $80{ }^{\circ} \mathrm{C}$, this material is in its rubbery state.

\section{Thermomechanical characterization}

The thermomechanical behavior of PPVC has been investigated at low and high strain rates, for temperatures ranging from -30 to $85{ }^{\circ} \mathrm{C}$. This corresponds to the glass transition region according to Fig. 5. During the lifetime of the structure, the temperature of the material can vary between -30 and $85^{\circ} \mathrm{C}$. Thus, this temperature range is classically used by the automotive industry to validate their materials. Tensile tests have been performed at low strain rates, until the failure of the material or the maximum displacement of the machine is achieved. Dynamic tests have been performed at high strain rates. The level of strain reached at the end of the dynamic test is not relevant. Thus, the level of strain reached under dynamic loading will not be analyzed, as we cannot link it to the failure. Equilibrium was reached for each test presented in this study.

\section{Mechanical behavior of PPVC}

Representative true stress-strain curves are plotted in Fig. 6. The temperature sensitivity of PPVC at $0.03 \mathrm{~s}^{-1}$ is plotted in Fig. 6a, and its strain rate sensitivity is plotted in Fig. 6b, c and d for three temperatures $\left(-30,23\right.$ and $85{ }^{\circ} \mathrm{C}$ ). For low strain rates, specimens have been tested under tensile loading, whereas for high strain rates, specimens were tested under compressive loading. However, no barreling effect is observed in dynamic conditions due to the low thickness/diameter ratio. Evolution of the thermomechanical behavior of PPVC is observed: from a viscoelastic-viscoplastic behavior to a rubbery behavior.

The true stress-strain curves presented in Fig. 6 show two stages: a short stage at the beginning of the curve corresponding to elastic, viscoelastic behavior, and a second stage characterized by non-linearity of the stress-strain curves. The slope of the curves in the second phase decreases as temperature increases. The material properties, elastic modulus and yield stress, increase when the temperature decreases as shown in Fig. 6a. For all specimens, no necking was observed during tensile tests. For the different tested strain rates and temperatures, all stress-strain curves show a major strain hardening. All specimens have been broken in the gauge length except those tested at $85^{\circ} \mathrm{C}$, where no failure was observed, as shown in Fig. 6a.

The strain rate sensitivity of PPVC is presented in Fig. $6 \mathrm{~b}, \mathrm{c}$ and $\mathrm{d}$ for three temperatures: firstly, $-30{ }^{\circ} \mathrm{C}$, close to the glass transition region (see Fig. 6b); secondly, at room temperature in the rubbery state (see Fig. 6c); thirdly, at $85{ }^{\circ} \mathrm{C}$ (see Fig. 6d). For all temperatures, the elastic modulus and the yield stress increase when the strain rate increases.

At low temperatures exemplified by Fig. $6 \mathrm{~b}$, $a$ change of mechanical behavior is observed between dynamic and quasi-static loadings. At high strain rate, PPVC exhibits a glassy behavior, whereas at low strain rate, it exhibits a viscoelastic-viscoplastic behavior. Then, the material is in its glass transition region $\left(T_{\mathrm{g}}=-32{ }^{\circ} \mathrm{C}\right.$; see DSC curves in Fig. 4). At high strain rates, PPVC demonstrates a classical mechanical behavior under compression loading; after a linear elastic response, a nonlinear response appears before the yield point. After this point, the material exhibits a plastic behavior. The viscoplasticity of the material can be divided into two domains: an initial strain softening domain, followed by a strain-hardening domain due to polymer chain alignment. At low strain rates, there is no strain softening. The viscoelastic stage is directly followed by the strain-hardening domain, until specimen failure occurs.

At room temperature, a change of behavior is also observed between high and low strain rates (see 

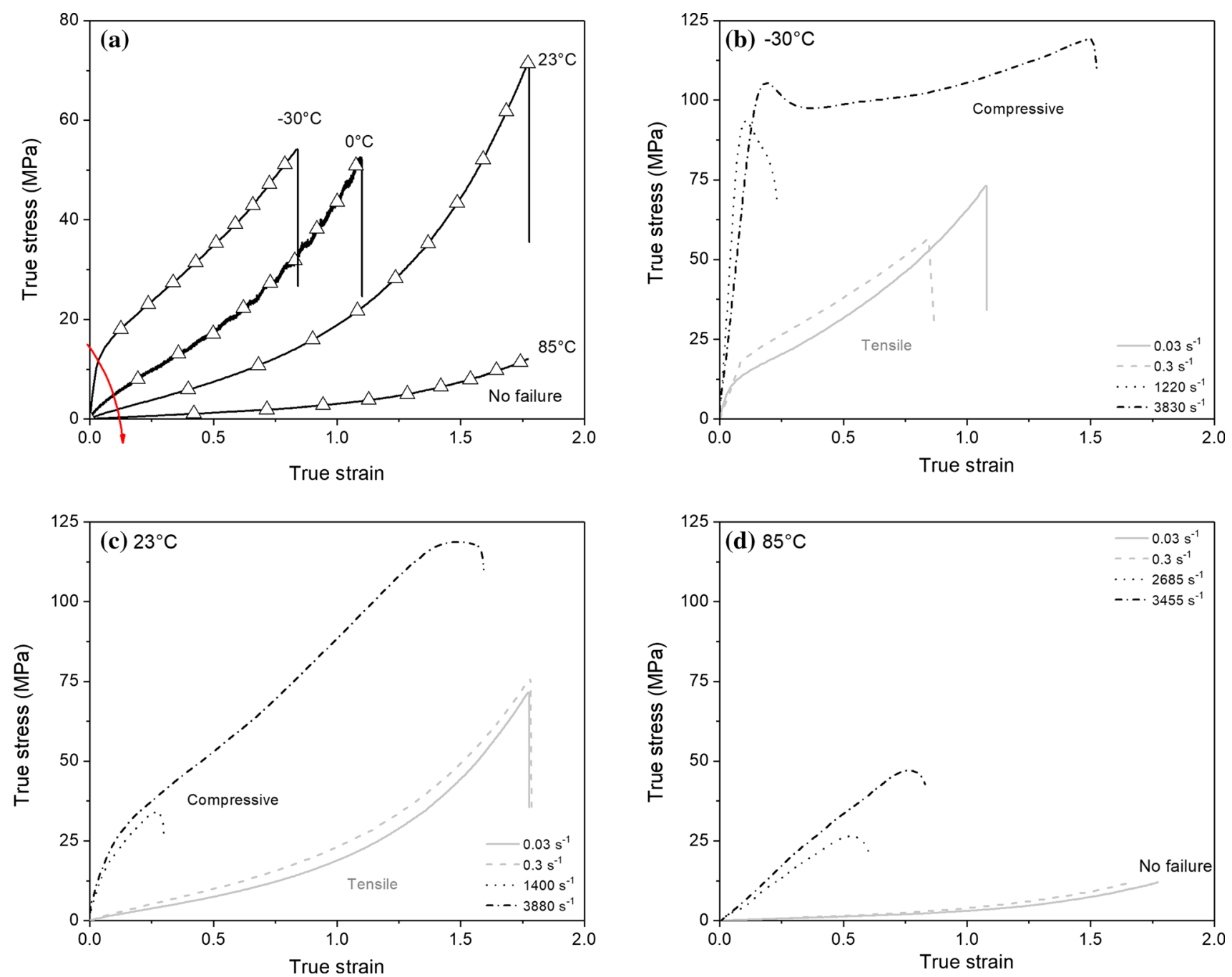

Figure 6 Experimental true stress-true strain curves under uniaxial quasi-static tensile loading and dynamic compressive loadings. a Temperature sensitivity at $0.03 \mathrm{~s}^{-1}$. Strain rate sensitivity at $\mathbf{b}-30{ }^{\circ} \mathrm{C}, \mathbf{c} 2{ }^{\circ} \mathrm{C}$ and $\mathbf{d ~} 85{ }^{\circ} \mathrm{C}$.

Fig. 6c). The mechanical behavior at high strain rates is close to that observed at low strain rates and temperature (see Fig. 6a). Thus, at room temperature and a high strain rate, PPVC exhibits a viscoelasticviscoplastic behavior. At room temperature and low strain rate (see Fig. $6 \mathrm{c}$ ) and at $85{ }^{\circ} \mathrm{C}$ at all strain rates (see Fig. 6d), PPVC presents a rubbery behavior.

By comparing Fig. $6 \mathrm{~b}, \mathrm{c}$, and $\mathrm{d}$, the temperature sensitivity of PPVC at high strain rate is clearly identified on the evolution of the flow stress. Moreover, the behavior of PPVC gradually changes from an elastic-viscoplastic behavior to a viscoelastic-viscoplastic one, followed by a hyper-viscoelastic behavior [41, 42].

\section{Temperature and strain rate sensitivity of material properties}

Elastic modulus, yield strain, yield stress, strain at break-point, and stress at break-point have been analyzed using the true stress-strain curves presented above. At low strain rates due to the low stiffness of the material, we use the nominal stressstrain curves to determine an accurate value for the elastic modulus and the onset of yield. Young's modulus is calculated from the initial slope of the true (or nominal) stress-strain curves. When the elastic-viscoelastic behavior of PPVC is followed by strain softening, the yield stress is taken as the maximum between these two stages. In cases where the stress-strain curves do not show a local maximum, 
the yield stress is defined as the intersection of the elastic and the plastic slopes.

Temperature sensitivity of material properties at low strain rates For a better understanding of the temperature sensitivity on the mechanical properties of PPVC, these are plotted in Fig. 7. The elastic modulus (see Fig. 7a), the yield stress, the stress at break-point (see Fig. $7 \mathrm{~b}$ ), the yield strain, and the elongation at breakpoint (see Fig. 7c) were plotted. Two strain rates are investigated. Figure 7a shows a nonlinear relationship between elastic modulus and temperature. At $-30{ }^{\circ} \mathrm{C}$, a discrepancy is found for the elastic modulus, due to the proximity of this temperature to the glass transition temperature. Above this temperature, the material is in a rubbery state. A nonlinear evolution was observed. At low temperature, and for a strain rate of $0.3 \mathrm{~s}^{-1}$, the elastic modulus could not be measured due to limitations of the experimental setup. In the rubbery region, between 23 and $85{ }^{\circ} \mathrm{C}$, the experimental data for the two strain rates are superimposed. This means that the strain rate sensitivity of PPVC is not significant in the rubbery region.

The temperature sensitivity of the yield stress and the stress at break-point is plotted in Fig. $7 \mathrm{~b}$. The yield stress decreases nonlinearly as the temperature increases, and it increases with the strain rate. The stress at break-point increases when the temperature increases or when the strain rate decreases. At $85{ }^{\circ} \mathrm{C}$, the samples did not break and the maximum displacement of the testing machine is reached before material failure. The strain rate sensitivity of PPVC is considerable at low temperature.

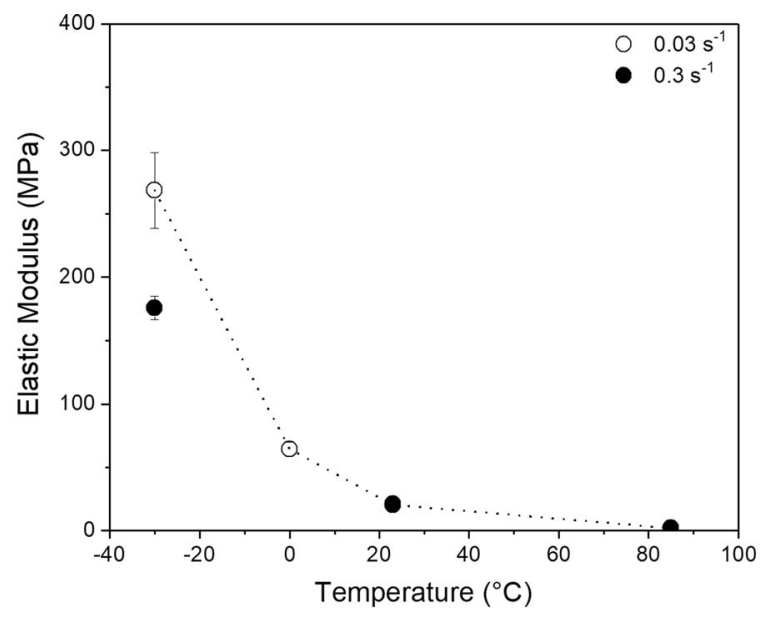

(a)

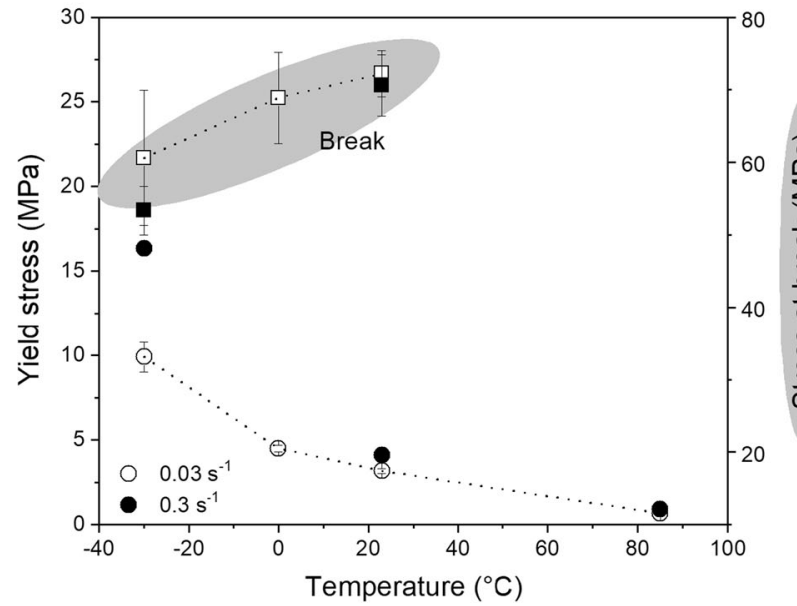

(b)

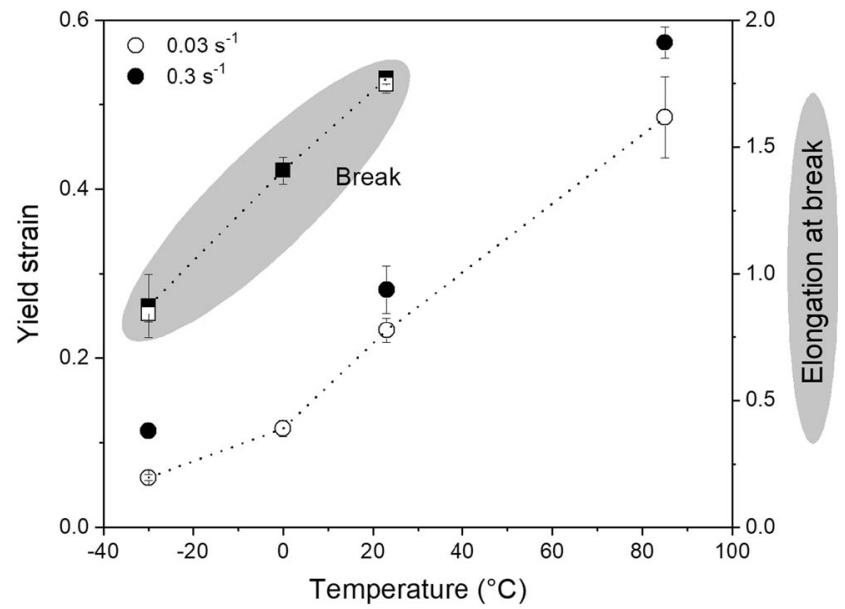

(c)

Figure 7 Temperature sensitivity at $\dot{\varepsilon}=0.03 \mathrm{~s}^{-1}$ and at $\dot{\varepsilon}=0.3 \mathrm{~s}^{-1}$ a elastic modulus, b yield stress and stress at break and c yield strain and elongation at break. 
In Fig. $7 \mathrm{c}$, the temperature sensitivity of the yield strain and the elongation at break-point are plotted for two strain rates: 0.03 and $0.3 \mathrm{~s}^{-1}$. These properties increase with temperature. The yield strain exhibits a nonlinear dependence on temperature, where a change of slope is observed at $0{ }^{\circ} \mathrm{C}$. Moreover, the yield strain increases when the strain rate increases. Contrary to the yield strain, the elongation at breakpoint does not seem to be influenced by the glass transition temperature. As for the stress at breakpoint, the elongation is linearly dependent on the inverse of the temperature.

The miscibility of plasticizers with PVC results in the formation of a physical network between the two materials. The plasticizer in this network [43] causes chain slippage and consequently high elongation at break-point for plasticizer components in blends [7].

All results presented in these sections come from a set of data. Thus, all include standard deviation. However, it can appear, for some results, very small standard deviation which is not visible on the figures.

Strain rate sensitivity of material properties The strain rate dependence of the elastic modulus, yield stress, and yield strain at three temperatures $(-30,23$, $85^{\circ} \mathrm{C}$ ) are presented in Fig. 8a, b, and c, respectively. $-30{ }^{\circ} \mathrm{C}$ is close to the glass transition temperature, while 23 and $85{ }^{\circ} \mathrm{C}$ are in the rubbery region. At high strain rates and $85{ }^{\circ} \mathrm{C}$, these material properties are not reported due to the hyper-elastic behavior of the material for these coupled conditions.

In Fig. 8a, we observe a major discrepancy of the elastic modulus at high strain rates. This phenomenon is due to the strong strain rate sensitivity of the elastic modulus in the glass transition region and a non-optimal dynamic equilibrium. Between quasistatic and dynamic loadings, an increase of the elastic modulus is observed.

Figure $8 \mathrm{~b}$ shows an increase in yield stress when the temperature decreases and the strain rate increases. At $23{ }^{\circ} \mathrm{C}$, the yield stress is bi-linearly dependent on the log of the strain rate. A drop in yield stress is observed between -30 and $23{ }^{\circ} \mathrm{C}$ due to the passage of the glass transition region.

In Fig. 8c, the strain rate dependency of the yield strain is plotted for the three temperatures tested. At low strain rates, the yield strain increases when the temperature and strain rate increase. However, at high strain rates, for the two temperatures considered $\left(-30\right.$ and $\left.23{ }^{\circ} \mathrm{C}\right)$, the yield strain increases when the strain rate increases but decreases when the temperature increases. Two assumptions can be formulated to explain this change of yield strain mechanical behavior between low and high strain rates. Firstly, we can consider that the modification in behavior is due to the change of behavior between quasi-static and dynamic loading upon the glass transition to a glassy region at $-30^{\circ} \mathrm{C}$ and from rubbery to a glass transition region at $23{ }^{\circ} \mathrm{C}$. Secondly, the change of behavior could be due to an increase in viscoelasticity at $23{ }^{\circ} \mathrm{C}$, as observed in Fig. 6. The same level of yield strain is obtained for the couples (low strain rates, $30{ }^{\circ} \mathrm{C}$ ) and (high strain rates, $23^{\circ} \mathrm{C}$ ), as shown in Fig. 8c. At $85^{\circ} \mathrm{C}$, in the rubbery region, a major discrepancy is observed due to the hyper-elastic behavior of the material at this temperature.

\section{Modeling}

\section{Storage modulus}

Several models described in the literature allow the evolution of the storage modulus from the glassy region to the rubbery region to be modeled [44-47]. Among them, the model developed by Mahieux and Reifsnider [44, 45] and improved by Richeton et al. [46] has been validated for a large number of polymers (amorphous and semicrystalline). The model is based on Weibull statistics to simulate the breakage of the secondary links:

$$
\begin{aligned}
E(T)= & \left(E_{1}-E_{2}\right) \exp \left(-\left(\frac{T}{T_{\beta}}\right)^{m_{1}}\right) \\
& +\left(E_{2}-E_{3}\right) \exp \left(-\left(\frac{T}{T_{\mathrm{g}}}\right)^{m_{2}}\right) \\
& +E_{3} \exp \left(-\left(\frac{T}{T_{\mathrm{m}}}\right)^{m_{3}}\right)
\end{aligned}
$$

where $E_{1}, E_{2}$ and $E_{3}$ are the instantaneous moduli of the material at the beginning of each region (glassy, glass transition, and rubbery). $T_{\beta}, T_{\mathrm{g}}$ and $T_{\mathrm{m}}$ are the temperatures of each transition (secondary relaxation, glass transition. and melting temperature) and $m_{i}$ are the Weibull moduli associated with the breakage of the secondary links.

This model is used to simulate the temperature sensitivity of the storage modulus observed at $1 \mathrm{~Hz}$ for the DMA test (see Fig. 5). The comparison between the DMA experimental results and the numerical predictions are presented in Fig. 9 for 


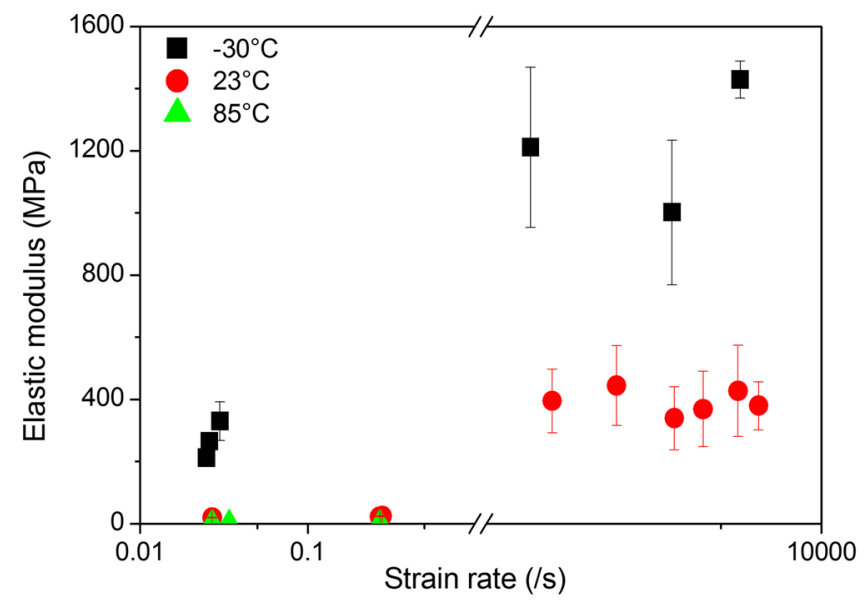

(a)

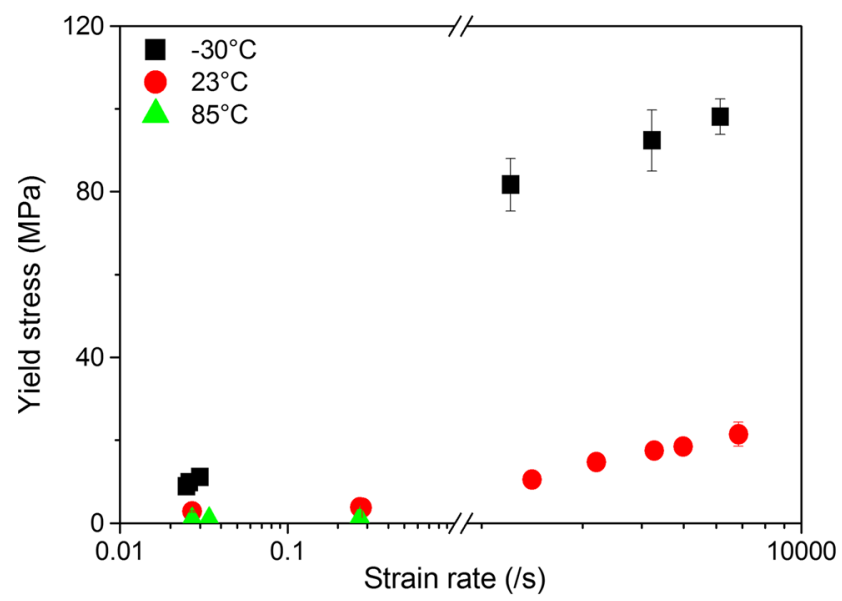

(b)

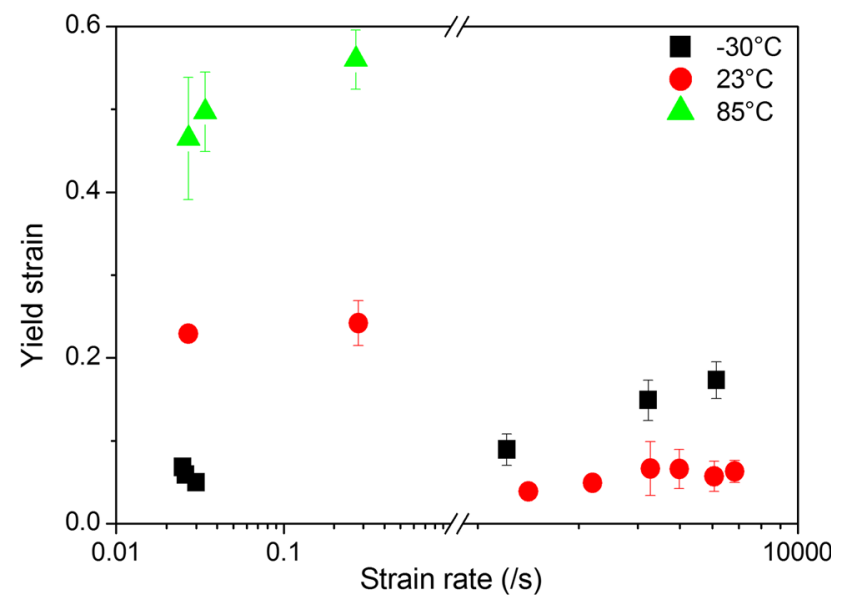

(c)

Figure 8 Strain rate sensitivity at three temperatures $\left(-30,23,85^{\circ} \mathrm{C}\right)$ a elastic modulus, $\mathbf{b}$ yield stress and $\mathbf{c}$ yield strain.

linear and logarithmic scales. A good agreement is observed between the experimental results and the numerical model calibrated with the parameters described in Table 1.

\section{Yield stress}

During recent decades, numerous models [46, 48-52] have been developed to model the strain rate and temperature dependencies of the yield stress. These models consider the yield stress as a thermally activated process. They allow modeling of the yield strength of glassy polymers over a wide range of strain rates and temperatures. However, few models allow reproduction of the yield stress in the glass transition and rubbery regions. Among those that do so, the cooperative model developed in our team by
Richeton et al. [46, 53] takes into account the drop of yield strength due to the glass transition temperature.

The cooperative model considers the cooperative jump motions of $n$ polymer chain segments. Lower than $T_{\mathrm{g}}$, it takes on the existence of an internal stress $\sigma_{\mathrm{i}}$, structural parameter which depicts the thermal history of the material. Higher than $T_{\mathrm{g}}$, the internal stress is null, allowing the flow of polymer chain segments. Thus, as a function of temperature, the internal stress is defined as [40]:

$\sigma_{\mathrm{i}}(T)= \begin{cases}\sigma_{\mathrm{i}}(0)-m T & \text { if } T<T_{\mathrm{g}} \\ 0 & \text { if } T \geq T_{\mathrm{g}}\end{cases}$

with $\sigma_{\mathrm{i}}(0)$ the internal stress at $0 \mathrm{~K}$ and $m$ a material parameter close to $\sigma_{\mathrm{i}}(0) / T_{\mathrm{g}}$. According to Fotheringham and Cherry $[54,55]$, the yield stress $\sigma_{\mathrm{y}}$ is given by: 

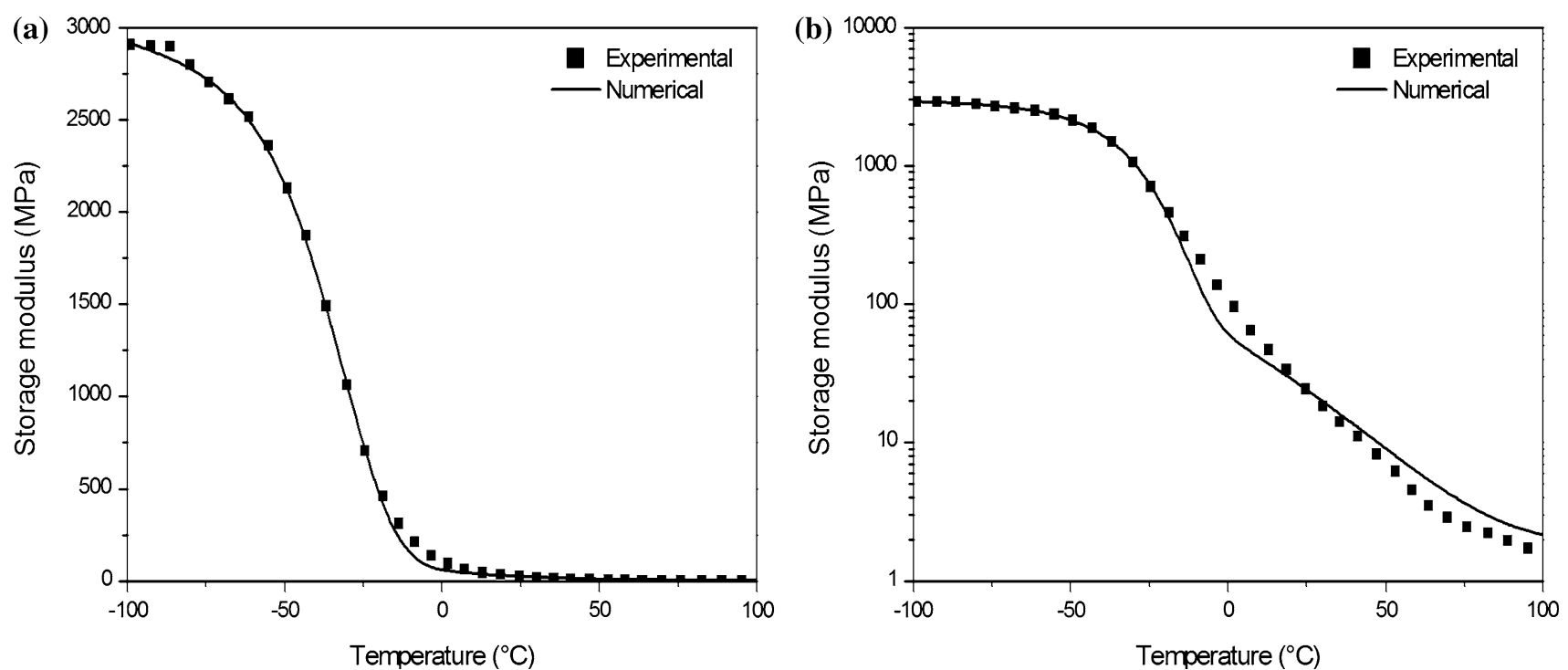

Figure 9 Numerical modeling of the storage modulus. Comparison between experimental results and numerical prediction in a linear and b logarithmic scale.

Table 1 Model parameters for the storage modulus [Eq. (1)]

\begin{tabular}{lllllllll}
\hline$E_{1}(\mathrm{MPa})$ & $E_{2}(\mathrm{MPa})$ & $E_{3}(\mathrm{MPa})$ & $T_{\beta}(\mathrm{K})$ & $T_{\mathrm{g}}(\mathrm{K})$ & $T_{\mathrm{m}}(\mathrm{K})$ & $m_{1}$ & $m_{2}$ & $m_{3}$ \\
\hline 3204 & 2413 & 1.8 & 210 & 243 & 700 & 3.5 & 15.9 & 25 \\
\hline
\end{tabular}

$\sigma_{\mathrm{y}}=\sigma_{\mathrm{i}}(T)+\frac{2 k T}{V} \sinh ^{-1}\left(\frac{\dot{\varepsilon}}{\dot{\varepsilon}^{*}(T)}\right)^{1 / n}$

with $k$ the Bolzmann constant, $T$ the absolute temperature, $\dot{\varepsilon}$ the strain rate, $V$ the activation volume, $\dot{\varepsilon}^{*}$ the characteristic strain rate and $n$ describing the cooperative character of the yield process. The temperature sensitivity of the characteristic strain rate is defined by:

$\dot{\varepsilon}^{*}= \begin{cases}\dot{\varepsilon}_{0} \exp \left(-\frac{\Delta H_{\beta}}{R T}\right) & \text { if } T<T_{\mathrm{g}} \\ \dot{\varepsilon}_{0} \exp \left(-\frac{\Delta H_{\beta}}{R T_{\mathrm{g}}}\right) \exp \left(\frac{\ln 10 c_{1}\left(T-T_{\mathrm{g}}\right)}{c_{2}+T-T_{\mathrm{g}}}\right) & \text { if } T \geq T_{\mathrm{g}}\end{cases}$

with $\Delta H_{\beta}$ the $\beta$ activation energy, $c_{1}, c_{2}$ the WLF parameters, $R$ the gas constant and $\dot{\varepsilon}_{0}$ a pre-exponential constant.

To build the master curve for the yield stress, a referenced temperature $T_{\text {ref }}$ is chosen and the time/ temperature superposition principle is applied. The horizontal and vertical shifts are given by:

$$
\left\{\begin{aligned}
\Delta(\log \dot{\varepsilon}) & =\log \dot{\varepsilon}\left(T_{\text {ref }}\right)-\log (\dot{\varepsilon}) \\
\Delta\left(\frac{\sigma_{\mathrm{y}}}{T}\right) & =\frac{\sigma_{y}\left(T_{\text {ref }}\right)}{T_{\text {ref }}}-\frac{\sigma_{\mathrm{y}}(T)}{T} .
\end{aligned}\right.
$$

In Fig. 10, the master curve is built at $-30{ }^{\circ} \mathrm{C}$ using the parameter presented in Table 2. An important dispersion of the experimental results is observed at high strain rates. However, a good agreement between experimental results and the numerical

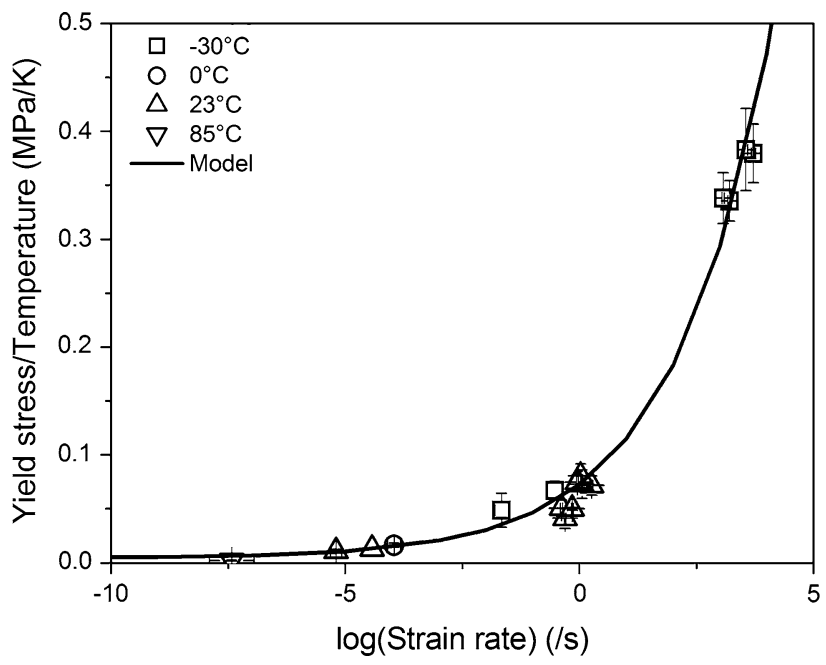

Figure 10 Master curve built at $-30{ }^{\circ} \mathrm{C}$ for the PPVC tested in uniaxial tension for low strain rates and uniaxial compression for high strain rates. 
Table 2 Model parameters for the cooperative model used to build the master curve at $-30{ }^{\circ} \mathrm{C}$

\begin{tabular}{llllll}
\hline$\Delta H_{\beta}\left(\mathrm{kJ} \mathrm{mol}^{-1}\right)$ & $\sigma_{\mathrm{i}}(0)(\mathrm{MPa})$ & $m\left(\mathrm{MPa} \mathrm{K}^{-1}\right)$ & $V\left(\mathrm{~m}^{3}\right)$ & $\dot{\varepsilon}_{0}\left(\mathrm{~s}^{-1}\right)$ & $n$ \\
\hline 10 & 5 & 0.016 & $3.6 \mathrm{E}-29$ & $1.5 \mathrm{E} 7$ & 4.78 \\
\hline
\end{tabular}

prediction can still be observed from quasi-static to dynamic strain rates.

\section{Conclusion}

Thermal, mechanical, and microscopic investigations have been performed on a multilayered PPVC for the automotive industry. Degassing phenomena occurring during the manufacturing process of the PPVC sheets induces $4 \%$ of voiding and increase to $6.7 \%$ after tensile tests. Moreover, testing specimens reveal the presence of sodium aluminosilicate clusters classically used component to stabilize PVC melts. These particles are parts of the $10 \%$ of additives added in the polymer formulation and the only one remaining after the thermal degradation of the material.

DSC measurements and DMA feature the temperature range of the study into the glass transition region of the material. This one is quite wide and extends from -40 to $80^{\circ} \mathrm{C}$. The thermomechanical tests performed in that study clearly illustrate the change of behavior of PPVC over the temperature range. From the glass transition region to the rubbery region for quasi-static tests and from glassy region to rubbery region for dynamic range, all the spectrum of behavior is analyzed. In the investigated range of temperature and strain rate, elastic modulus, yield stress, and yield strain exhibit a nonlinear behavior with a change of slope around $0{ }^{\circ} \mathrm{C}$ (peak of the $\tan \delta$ curve). In the case of the stress at break and elongation at break-point, linear evolution is observed in the studied temperature range. Modeling of the storage modulus and yield stress were also performed and a good agreement was found between the numerical prediction and the experimental results.

\section{Acknowledgements}

The authors thank Professor Christophe Fond and Assistant Professor Rigoberto Ibarra for their helpful discussions.

\section{References}

[1] Wang Y, Arruda EM, Przybylo PA (2001) Characterization and constitutive modeling of a plasticized poly(vinyl chloride) for a broad range of strain rates. Rubber Chem Technol 74:560-573. https://doi.org/10.5254/1.3544957

[2] Aubin M, Prud'homme RE (1988) Analysis of the glass transition temperature of miscible polymer blends. Macromolecules 21:2945-2949. https://doi.org/10.1021/ma00188 a010

[3] Lu X, Weiss RA (1992) Relationship between the glass transition temperature and the interaction parameter of miscible binary polymer blends. Macromolecules 25:3242-3246. https://doi.org/10.1021/ma00038a033

[4] Pezzin G, Zilio-Grandi F, Sanmartin P (1970) The dependence of the glass transition temperature on molecular weight for polyvinylchloride. Eur Polym J 6:1053-1061. https://doi.org/10.1016/0014-3057(70)90038-8

[5] Gibbs JH, DiMarzio EA (1958) Nature of the glass transition and the glassy state nature of the glass transition and the glassy state. AIP J Chem Phys 28:373-383

[6] Somcynsky T, Patterson D (1962) The glass transition and the reduced temperature of polymeric liquids. J Polym Sci 62:S151-S155. https://doi.org/10.1002/pol.1962.1206217 460

[7] Varughese KT, Nando GB, De SK, Sanyal SK (1989) Tensile and tear failure of plasticized poly (vinyl chloride)/epoxidized natural rubber miscible blends. J Mater Sci 24:3491-3496. https://doi.org/10.1007/BF02385730

[8] Ha C-S, Kim Y, Lee W-K, Cho W-J, Kim Y (1998) Fracture toughness and properties of plasticized PVC and thermoplastic polyurethane blends. Polymer 39:4765-4772. https:// doi.org/10.1016/S0032-3861(97)10326-3

[9] Roy KJ, Anjali TV, Sujith A (2017) Asymmetric membranes based on poly(vinyl chloride): effect of molecular weight of additive and solvent power on the morphology and performance. J Mater Sci 52:5708. https://doi.org/10.1007/s10853017-0807-1

[10] MJ Kendall, CR Siviour (2012) Strain rate dependence in plasticized and un-plasticized PVC. In: EPJ Web of Conferences, vol 26. https://doi.org/10.1051/epjconf/20122602009

[11] Kendall MJ, Siviour CR (2014) Rate dependence of poly(vinyl chloride), the effects of plasticizer and time-temperature superposition. Proc R Soc Lond A Math Phys Eng Sci. https://doi.org/10.1098/rspa.2014.0012 
[12] Zhang H, Hu X, Chen Y et al (2015) Dynamic rheological property and membrane formation of mechanochemically modified polyvinylchloride. J Mater Sci 50:4371-4378. https://doi.org/10.1007/s10853-015-8991-3

[13] Bernard CA, Bahlouli N, Wagner-Kocher C, Ahzi S, Rémond Y (2015) Impact behaviour of an innovative plasticized poly(vinyl chloride) for the automotive industry. https://doi.org/10.1051/epjconf/20159402013

[14] Mulliken AD, Soong SY, Boyce MC, Cohen RE (2006) High-rate thermomechanical behavior of poly(vinyl chloride) and plasticized poly(vinyl chloride). J Phys IV France 134:217-223. https://doi.org/10.1051/jp4:2006134033

[15] Matuana LM, Park CB, Balatinecz JJ (1997) The effect of low levels of plasticizer on the rheological and mechanical properties of polyvinyl chloride/newsprint-fiber composites. J Vinyl Addit Technol 3:265-273. https://doi.org/10.1002/ vnl. 10204

[16] Marcilla A, Beltrán M (1998) Effect of the plasticizer concentration and heating rate on the thermal decomposition behaviour of PVC plastisols. Kinetic analysis. Polym Degrad Stab 60:1-10. https://doi.org/10.1016/S0141-3910(96)00124-3

[17] Altenhofen da Silva M, Adeodato Vieira MG, Gomes Maçumoto AC, Beppu MM (2011) Polyvinylchloride (PVC) and natural rubber films plasticized with a natural polymeric plasticizer obtained through polyesterification of rice fatty acid. Polym Testing 30:478-484. https://doi.org/10.1016/j. polymertesting.2011.03.008

[18] Ceccorulli G, Pizzoli M, Scandola M (1987) Composition dependence of the glass transition temperature of polymerdiluent systems: 1. Experimental evidence of a dual behaviour in plasticized PVC. Polymer 28:2077-2080. https:// doi.org/10.1016/0032-3861(87)90044-9

[19] Rehm T (1997) The compression set of plasticized PVC. J Vinyl Addit Technol 3:286-291. https://doi.org/10.1002/ vnl. 10208

[20] Pita VJRR, Sampaio EEM, Monteiro EEC (2002) Mechanical properties evaluation of $\mathrm{PVC} /$ plasticizers and $\mathrm{PVC} /$ thermoplastic polyurethane blends from extrusion processing. Polym Testing 21:545-550. https://doi.org/10.1016/ S0142-9418(01)00122-2

[21] Elicegui A, del Val JJ, Bellenger V, Verdu J (1997) A study of plasticization effects in poly(vinyl chloride). Polymer 38:1647-1657. https://doi.org/10.1016/S0032-3861(96)00 $671-4$

[22] Thomas S, Kuriakose B, Gupta BR, De SK (1986) Scanning electron microscopy studies on tensile, tear and abrasion failure of plasticized poly (vinyl chloride) and copolyester thermoplastic elastomers. J Mater Sci 21:711-716. https:// doi.org/10.1007/BF01145545
[23] Diani J, Gilormini P, Frédy C, Rousseau I (2012) Predicting thermal shape memory of crosslinked polymer networks from linear viscoelasticity. Int J Solids Struct 49(5):793-799

[24] Dixit M, Mathur V, Gupta S, Baboo M, Sharma K, Saxena NS (2009) Investigation of miscibility and mechanical properties of PMMA/PVC blends. Optoelectr Adv Mater Rapid Commun 3(10):1099-1105

[25] Matadi R, Hablot E, Wang K, Bahlouli N, Ahzi S, Avérous L (2011) High strain rate behaviour of renewable biocomposites based on dimer fatty acid polyamides and cellulose fibres. Compos Sci Technol 71:674-682. https://doi.org/10. 1016/j.compscitech.2011.01.010

[26] Wang K, Addiego F, Laachachi A, Kaouache B, Bahlouli N, Toniazzo V, Ruch D (2014) Dynamic behavior and flame retardancy of HDPE/hemp short fiber composites: effect of coupling agent and fiber loading. Compos Struct 113:74-82. https://doi.org/10.1016/j.compstruct.2014.03.009

[27] Wang K, Addiego F, Bahlouli N, Ahzi S, Rémond Y, Toniazzo V (2014) Impact response of recycled polypropylene-based composites under a wide range of temperature: effect of filler content and recycling. Compos Sci Technol 95:89-99. https://doi.org/10.1016/j.compscitech.2014.02. 014

[28] Bahlouli N, Pessey D, Raveyre C, Guillet J, Ahzi S, Dahoun A, Hiver JM (2012) Recycling effects on the rheological and thermomechanical properties of polypropylene-based composites. Mater Des 33:451-458. https://doi.org/10.1016/j. matdes.2011.04.049

[29] Lee O, Kim M (2003) Dynamic material property characterization by using split Hopkinson pressure bar (SHPB) technique. Nucl Eng Des 226:119-125. https://doi.org/10. 1016/S0029-5493(03)00189-4

[30] Pessey D, Bahlouli N, Pattofatto S, Ahzi S (2008) Polymer composites for the automotive industry: characterisation of the recycling effect on the strain rate sensitivity. Int $\mathrm{J}$ Crashworthiness 13:411-424. https://doi.org/10.1080/ 13588260802030745

[31] Gong F, Feng M, Zhao C, Zhang S, Yang M (2004) Thermal properties of poly(vinyl chloride)/montmorillonite nanocomposites. Polym Degrad Stab 84:289-294. https:// doi.org/10.1016/j.polymdegradstab.2003.11.003

[32] Yao Q, Wilkie CA (2001) Thermal degradation of PVC in the presence of polystyrene. J Vinyl Addit Technol 7:26-36. https://doi.org/10.1002/vnl.10261

[33] Soudais Y, Moga L, Blazek J, Lemort F (2007) Coupled DTA-TGA-FT-IR investigation of pyrolytic decomposition of EVA, PVC and cellulose. J Anal Appl Pyrolysis 78:46-57. https://doi.org/10.1016/j.jaap.2006.04.005 
[34] Bacaloglu R, Fisch M (1994) Degradation and stabilization of poly(vinyl chloride). I. Kinetics of the thermal degradation of poly(vinyl chloride). Polym Degrad Stab 45:301-313

[35] Marongiu A, Faravelli T, Bozzano G, Dente M, Ranzi E (2003) Thermal degradation of poly(vinyl chloride). J Anal Appl Pyrol 70:519-553. https://doi.org/10.1016/S01652370(03)00024-X

[36] Lindström A, Hakkarainen M (2006) Environmentally friendly plasticizers for poly(vinyl chloride)_improved mechanical properties and compatibility by using branched poly(butylene adipate) as a polymeric plasticizer. J Appl Polym Sci 100:2180-2188. https://doi.org/10.1002/app. 23633

[37] Barton JM (1979) Thermoanalytical study of an epoxy resin crosslinked with an aliphatic polyamine. Thermochim Acta 30:153-161. https://doi.org/10.1016/0040-6031(79)85050-9

[38] Kumler PL, Machajewski GA, Fitzgerald JJ, Denny LR, Keinath SE, Boyer RF (1987) Detection of Tll in styreneethyl acrylate random copolymers by differential scanning calorimetry and dynamic mechanical analysis. Macromolecules 20:1060-1065. https://doi.org/10.1021/ ma00171a032

[39] Cassel B, Twombly B (1991) Glass transition determination by thermomechanical analysis, a dynamic mechanical analyzer, and a differential scanning calorimeter. In: Materials characterization by thermomechanical analysis, ASTM International, 1991

[40] Achorn PJ, Ferrillo RG (1994) Comparison of thermal techniques for glass transition measurements of polystyrene and cross-linked acrylic polyurethane films. J Appl Polym Sci 54:2033-2043

[41] Oshmyan V, Patlazhan S, Remond Y (2004) Simulation of small-strain deformations of semi-crystalline polymer: coupling of structural transformations with stress-strain response. J Mater Sci 39:3577-3586. https://doi.org/10. 1023/B:JMSC.0000030709.19754.28

[42] Patlazhan S, Remond Y (2012) Structural mechanics of semicrystalline polymers prior to the yield point: a review. J Mater Sci 47:6749-6767. https://doi.org/10.1007/s10853012-6620-y

[43] Pitaa VJRR, Sampaiob EEM, Monteiroa EEC (2002) Mechanical properties evaluation of PVC/plasticizers and PVC/thermoplastic polyurethane blends from extrusion processing. Polym Testing. https://doi.org/10.1016/S01429418(01)00122-2
[44] Mahieux C, Reifsnider K (2001) Property modeling across transition temperatures in polymers: a robust stiffness-temperature model. Polymer 42:3281-3291. https://doi.org/10. 1016/S0032-3861(00)00614-5

[45] Mahieux CA, Reifsnider KL (2002) Property modeling across transition temperatures in polymers: application to thermoplastic systems. J Mater Sci 37:911-920. https://doi. org/10.1023/A:1014383427444

[46] Richeton J, Ahzi S, Daridon L, Rémond Y (2005) A formulation of the cooperative model for the yield stress of amorphous polymers for a wide range of strain rates and temperatures. Polymer 46:6035-6043. https://doi.org/10. 1016/j.polymer.2005.05.079

[47] Dupaix RB, Boyce MC (2007) Constitutive modeling of the finite strain behavior of amorphous polymers in and above the glass transition. Mech Mater 39:39-52. https://doi.org/ 10.1016/j.mechmat.2006.02.006

[48] Eyring H (1936) Viscosity, plasticity, and diffusion as examples of absolute reaction rates. J Chem Phys 4:283-291

[49] Robertson RE (1966) Theory for the plasticity of glassy polymers. J Chem Phys 44:3950-3956

[50] Argon AS (1973) A theory for the low-temperature plastic deformation of glassy polymers. Philos Mag 28:839-865. https://doi.org/10.1080/14786437308220987

[51] Bowden PB, Raha S (1974) A molecular model for yield and flow in amorphous glassy polymers making use of a dislocation analogue. Philos Mag 29:149-166. https://doi.org/10. 1080/14786437408213560

[52] Ree T, Eyring H (1955) Theory of non-newtonian flow. I. Solid plastic system. J Appl Phys 26:793-800

[53] Richeton J, Ahzi S, Vecchio KS, Jiang FC, Adharapurapu RR (2006) Influence of temperature and strain rate on the mechanical behavior of three amorphous polymers: characterization and modeling of the compressive yield stress. Int $\mathrm{J}$ Solids Struct 43:2318-2335. https://doi.org/10.1016/j. ijsolstr.2005.06.040

[54] Fotheringham D, Cherry BW, Bauwens-Crowet C (1976) Comment on "the compression yield behaviour of polymethyl methacrylate over a wide range of temperatures and strain-rates”. J Mater Sci 11:1368-1371. https://doi.org/10. 1007/BF00545162

[55] Fotheringham DG, Cherry BW (1978) The role of recovery forces in the deformation of linear polyethylene. J Mater Sci 13:951-964. https://doi.org/10.1007/BF00544690 